\title{
TU/e emonown

\section{Effect of dye doping on the charge carrier balance in PPV light emitting diodes as measured by admittance spectroscopy}

\section{Citation for published version (APA):}

Hulea, I. N., Scheer, van der, R. F. J., Brom, H. B., Langeveld-Voss, B. M. W., Dijken, van, A., \& Brunner, K. (2003). Effect of dye doping on the charge carrier balance in PPV light emitting diodes as measured by admittance spectroscopy. Applied Physics Letters, 83(6), 1246-1/3. https://doi.org/10.1063/1.1600850

DOI:

10.1063/1.1600850

Document status and date:

Published: 01/01/2003

\section{Document Version:}

Publisher's PDF, also known as Version of Record (includes final page, issue and volume numbers)

\section{Please check the document version of this publication:}

- A submitted manuscript is the version of the article upon submission and before peer-review. There can be important differences between the submitted version and the official published version of record. People interested in the research are advised to contact the author for the final version of the publication, or visit the $\mathrm{DOI}$ to the publisher's website.

- The final author version and the galley proof are versions of the publication after peer review.

- The final published version features the final layout of the paper including the volume, issue and page numbers.

Link to publication

\section{General rights}

Copyright and moral rights for the publications made accessible in the public portal are retained by the authors and/or other copyright owners and it is a condition of accessing publications that users recognise and abide by the legal requirements associated with these rights.

- Users may download and print one copy of any publication from the public portal for the purpose of private study or research.

- You may not further distribute the material or use it for any profit-making activity or commercial gain

- You may freely distribute the URL identifying the publication in the public portal.

If the publication is distributed under the terms of Article 25fa of the Dutch Copyright Act, indicated by the "Taverne" license above, please follow below link for the End User Agreement:

www.tue.nl/taverne

Take down policy

If you believe that this document breaches copyright please contact us at:

openaccess@tue.nl

providing details and we will investigate your claim. 


\title{
Effect of dye doping on the charge carrier balance in PPV light emitting diodes as measured by admittance spectroscopy
}

\author{
I. N. Hulea, ${ }^{\text {a) }}$ R. F. J. van der Scheer, ${ }^{\text {b) }}$ and H. B. Brom \\ Kamerlingh Onnes Laboratory, Leiden University, P.O. Box 9504, 2300 RA Leiden, The Netherlands \\ Bea M. W. Langeveld-Voss \\ TNO Industrial Technology, De Wielen 6, 5600 HE Eindhoven, The Netherlands
}

A. van Dijken and K. Brunner

Philips Research Laboratories, Prof. Holstlaan 4, 5656 AA Eindhoven, The Netherlands

(Received 22 January 2003; accepted 23 June 2003)

\begin{abstract}
Dye doping is a promising way to increase the spectral purity of polymer light-emitting diodes (LEDs). Here we analyze the frequency and field dependence of the complex admittance of $\mathrm{Al}-\mathrm{Ba}-\mathrm{PPV}-$ poly(3,4-ethylenedioxythiophene:polystyrene sulphonic acid)-indium tin oxide LEDs with and without dye. We compare the charge carrier mobilities of pristine and dye-doped double-carrier and hole-only (Au replacing $\mathrm{Al}-\mathrm{Ba}$ ) devices. Dye doping is shown to significantly influence the electron mobilities while the hole mobilities are left unchanged and thereby changing the carrier balance in a double carrier device towards that of a hole only device. The minimum in the LED capacitance as a function of voltage appears to be an excellent probe for the electron trapping phenomenon underlying the reduction of the mobility. (C) 2003 American Institute of Physics. [DOI: 10.1063/1.1600850]
\end{abstract}

Although an obvious route for true full-color light emitting diodes (LEDs) is employing three different polymers for the primary colors, there are several other approaches currently being examined. A particular appealing solution is energy or charge transfer from a host polymer to emissive guest molecules. This process can be optimized to virtually a hundred percent efficiency already at low guest concentrations, which should leave the macroscopic properties of the polymer, such as viscosity, unchanged. The latter is particularly important for the efficient production of pixelated devices by ink-jet printing because the printing process has to be optimized only for one ink instead of three. For these applications detailed knowledge about the changes of the charge carrier properties upon adding guest molecules to a host polymer is desired. Low-frequency admittance data of LEDs have been proven to give valuable information about the mobility of charge carriers. ${ }^{1}$ Here we measure the diode admittance as a function of bias voltage at low frequencies and compare devices with and without an emissive guest (dye dopant) in the active polymer layer. When we increase the bias voltage $V$ above the built-in voltage $V_{\mathrm{bi}}$, the diode capacitance $C_{p}$ shows a minimum that (i) is markedly different for hole-only (HO) and double-carrier (DC) devices and (ii) is strongly dependent on the doping concentration. In pristine samples and at low doping concentrations a formally negative $C_{p}$ is measured at low frequencies. ${ }^{2}$ By comparing admittance data for DC and $\mathrm{HO}$ devices, the capacitance minimum at a voltage just above $V_{\text {bi }}$ proves to be an excellent probe for electron trapping and mobility. It will be shown

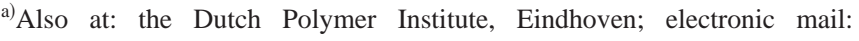
hulea@phys.leidenuniv.nl

b) Also at: the Eindhoven University of Technology. that on the time scale of our measurement dye doping in these devices effectively changes the device from a double carrier towards an electron deficient device.

All samples were prepared in a glove box under $\mathrm{N}_{2}$ atmosphere. A polymer/toluene solution containing $4.5 \mathrm{mg} / \mathrm{ml}$ polymer is stirred at room temperature over night and heated at $70^{\circ} \mathrm{C}$ for $1 \mathrm{~h}$ before the dye is added from a stock solution in toluene $(4 \mathrm{mg} / \mathrm{ml})$. After stirring again for $1 \mathrm{~h}$, the mixture is filtered over a $5 \mu \mathrm{m}$ filter. The glass substrates, covered with a $120 \mathrm{~nm}$ transparent and patterned indium tin oxide (ITO) layer $(<20 \Omega / \square)$, were exposed to ultraviolet radiation in an ozone atmosphere for $10 \mathrm{~min}$ prior to spin coating. Remaining dust particles were blown away with ionized nitrogen before $150 \pm 5 \mathrm{~nm}$ of a conducting polymer [poly $(3,4-$ ethylenedioxythiophene:polystyrene sulphonic acid) (PEDOT:PSS) from Bayer AG] and $70 \pm 5 \mathrm{~nm}$ of an emissive polymer were spin coated on the substrates. The diode structures consist of Al-Ba-PPV-PEDOT:PSS-ITO for the DC device and Au-PPV-PEDOT:PSS-ITO for the HO device. All devices have a surface area of $100 \mathrm{~mm}^{2}$ typically and are encapsulated. The yellow emitting PPV-based polymer was prepared via the Gilch polymerization route. ${ }^{3}$ The synthesis of the red dye will be published elsewhere and its structure can be found in Fig. 2. From ultraviolet photoemission spectroscopy (UPS) [highest occupied molecular orbital (HOMO) of the polymer] and cyclovoltammetry measurements [HOMO and lowest unoccupied molecular orbital (LUMO) of dye and polymer] the LUMO-HOMO levels have been determined for both host and dye. For the yellow PPV the HOMO is at $5.2 \mathrm{eV}$ below the vacuum level and the LUMO at $2.9 \mathrm{eV}$. For the dye, the HOMO is at $5.4 \mathrm{eV}$ and the LUMO at $3.5 \mathrm{eV}$. The levels for PEDOT-PSS and $\mathrm{Al}-\mathrm{Ba}$ are at 5 and $2.3-2.6 \mathrm{eV}$, respectively.

In impedance measurements a LED can be seen as a 

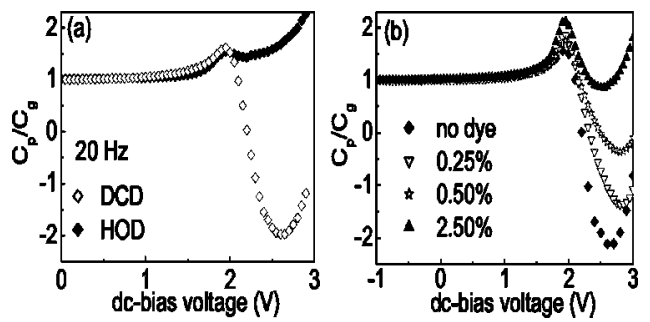

FIG. 1. (a) $C_{p} / C_{g}$ vs bias voltage for a $\mathrm{HO}$ and DC device (HOD resp. DCD) at $20 \mathrm{~Hz}$. The HOD curve is shifted by $1.50 \mathrm{~V}$ towards more positive bias to overlap $V_{\mathrm{bi}}$. (b) $C_{p} / C_{g}$ vs bias voltage for different dye-doping concentrations in a DCD.

voltage and frequency dependent capacitance $\left[C_{p}(\omega, V)\right]$ and resistance $\left[R_{p}(\omega, V)\right]$ in parallel, so that the admittance $(Y)$ can be written as the sum of the conductance $G=1 / R_{p}$ and the susceptance $B=\omega C_{p}: Y=G+i B . Y$ was measured with an Agilent 4284a RCL meter. The amplitude of the ac voltage applied on top of the dc bias $(-2-5 \mathrm{~V})$ was $50 \mathrm{mV}$.

Figure 1(a) shows $C_{p} / C_{g}$ as a function of dc bias for a DC and $\mathrm{HO}$ device without dye at $20 \mathrm{~Hz}$. The geometrical capacitance $C_{g}$ is measured in the fully depleted state of the device at negative voltages. Especially the region just above $V_{\mathrm{bi}}$ will be shown to contain valuable information about the changes in the device as a function of dye doping. For a DC device $C_{p}(V) / C_{g}$ decreases very rapidly to a minimum of -2 , while $R_{p}$ decreases continuously. When the dc bias is increased further, the capacitance increases again. The increase in capacitance below $V_{\mathrm{bi}}$ has been observed before for thermally converted precursor $\mathrm{PPV}^{4}$ and will be dealt with in a separate contribution. $C_{p}(V)$ and $R_{p}(V)$ of a $\mathrm{HO}$ device can be described analogous to a DC device, see Fig. 1(a). Due to the differences in the built-in voltages the position of the maximum of $C_{p}(V) / C_{g}$ is at $0.45 \pm 0.05 \mathrm{~V}$ for the $\mathrm{HO}$ device and at $1.95 \pm 0.05 \mathrm{~V}$ for the DC device. In Fig. 1(a) the $\mathrm{HO}$ curve has been shifted by $1.50 \mathrm{~V}$ so that its maximum coincides with that of the DC curve. Both curves have a (local) minimum in $C_{p}(V) / C_{g}$ above the built-in voltage $V_{\mathrm{bi}}$. In Fig. 1(b) the effect of dye doping on the capacitance of a DC device is shown. The minimum capacitance above the built-in voltage gradually increases upon increasing the dopant concentration and already for a concentration of $2.5 \%$ its value approaches that of a $\mathrm{HO}$ device.

Since the obvious difference between DC devices and $\mathrm{HO}$ devices is the presence of electrons, it is tempting to associate the changes of the capacitance minimum above the built-in voltage upon dye doping to the response of the electrons participating in the current transport. In order to substantiate this assumption the charge transport properties of positive and negative charge carriers have to be evaluated and brought into relation to $C_{p}$. Frequency scans ${ }^{1}$ provide a simple way to derive the mobility $(\mu)$ by plotting $-\Delta B$ vs $\omega / 2 \pi$, see Fig. 2. The characteristic time $\tau_{r}=1 / \omega_{r}$ (at $\omega_{r}$ the maximum in $\Delta B$ appears) is related to the transit time $\tau_{t}$ of the charge carriers via $\tau_{r}=0.29 \tau_{t} .{ }^{1}$ This nondestructive measurement gives electron and hole mobilities at the same time and is done on the device as used in applications.

If the electrical field $(E)$ dependence of the carrier mobility $\mu$ in these disordered organic semiconductors is described by $\mu=\mu(0) \exp (\gamma \sqrt{E})$, we obtain for the zero field hole mobilities in the pristine $\mathrm{HO}$ and $\mathrm{DC}$ devices a value of Downloaded 20 Dec 2007 to 131.155.109.134. Redistribution subject

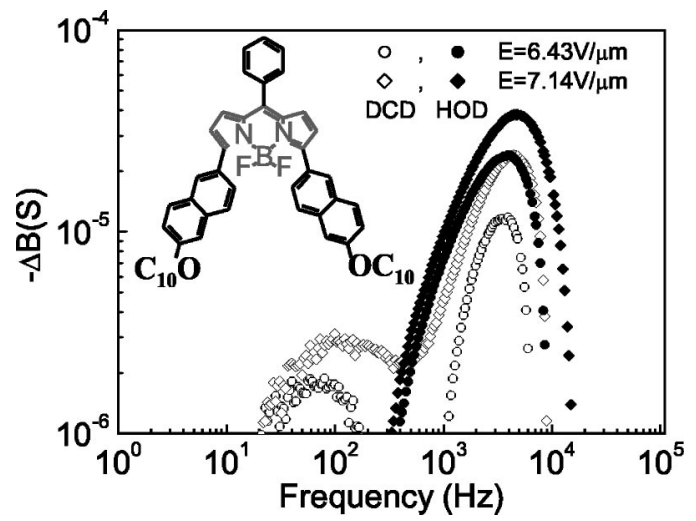

FIG. 2. Determination of $\mu_{e}$ and $\mu_{h}$ from $-\Delta B=-\omega\left(C-C_{g}\right)$ vs $\omega / 2 \pi$ for the $2.5 \%$ dye-doped sample. Inset shows the molecular structure of the dye.

$\mu(0)_{h}=1.12 \pm 0.1 \times 10^{-11} \mathrm{~m}^{2} / \mathrm{V} \mathrm{s}$ with an activation field factor $\gamma=7.12 \pm 0.7 \times 10^{-4}(\mathrm{~m} / \mathrm{V})^{1 / 2}$. The electron mobility in the pristine DC device is found to be nearly two orders of magnitude lower $\mu(0)_{e}=5.7 \pm 0.9 \times 10^{-13} \mathrm{~m}^{2} / \mathrm{V} \mathrm{s}$ with $\gamma$ $=8.9 \pm 1.2 \times 10^{-4}(\mathrm{~m} / \mathrm{V})^{1 / 2}$.

For dye-doped samples $\mu_{h}$ hardly changes (within 10\%) with the dye concentration. This is not a surprising result since it was established before by current-voltage scans of HO devices that the dye does not influence the current density of such devices. Furthermore, if the HOMO of a dopant is situated energetically below the HOMO of the host, as is the case in our system, the hole transport is not expected to be affected. ${ }^{5}$ However, the situation is considerably different for the electron mobilities. For $2.5 \%$ dye, $\mu(0)_{e}$ is reduced from $5.7 \pm 0.9 \times 10^{-13} \mathrm{~m}^{2} / \mathrm{V} \mathrm{s}$ to $3.8 \pm 0.6 \times 10^{-14} \mathrm{~m}^{2} / \mathrm{V} \mathrm{s}$ and the activation field factor is increased from $\gamma=8.9$ $\pm 1.2 \times 10^{-4}(\mathrm{~m} / \mathrm{V})^{1 / 2}$ to $\gamma=13.9 \pm 2 \times 10^{-4}(\mathrm{~m} / \mathrm{V})^{1 / 2}$. For a field of $7.5 \mathrm{~V} / \mu \mathrm{m} \mu_{e}$ will be $1.7 \times 10^{-12} \mathrm{~m}^{2} / \mathrm{V} \mathrm{s}$, about three times lower than in the pristine sample.

The influence of the dye dopant on the total current of a DC device is calculated at the fixed measurement frequency of $20 \mathrm{~Hz}$ using the replacement circuit in Fig. 3. The circuit includes explicitly the experimental values determined for the HO device (dashed box) to which in parallel the $R_{c}-L_{c}$ branch is added to account for the electron current and the increase in hole current compared to the $\mathrm{HO}$ device due to the changed charge distribution and the recombination in a

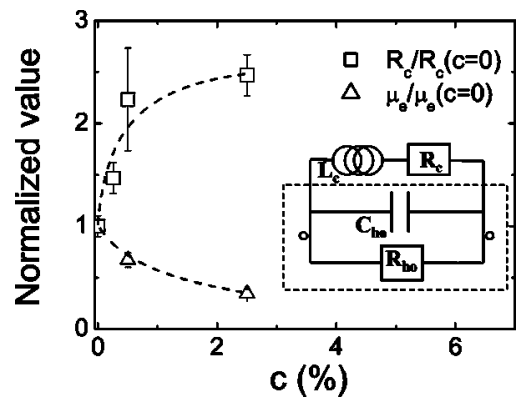

FIG. 3. The dye concentration (c) dependence of $\mu_{e}$ and $R_{c}$ at $E$ $=7.5 \mathrm{~V} / \mu \mathrm{m}$ using the replacement circuit (at $20 \mathrm{~Hz}$ ) shown in the inset. All values are normalized to those in the DC device without dye doping at $E$ $=7.5 \mathrm{~V} / \mu \mathrm{m}: R_{c}=1.7 \mathrm{k} \Omega$ and $\mu_{e}=4.9 \times 10^{-12} \mathrm{~m}^{2} / \mathrm{V} \mathrm{s} . L_{c} \approx 0.4 \mathrm{H}$ depends hardly on $c$, but decreases with increasing $E$ (for $c=0$ from $0.4 \mathrm{H}$ at $E$ $=7.5 \mathrm{~V} / \mu \mathrm{m}$ to $0.13 \mathrm{H}$ at $E=10.5 \mathrm{~V} / \mu \mathrm{m})$, while $R_{c}$ decreases from 1.7 to $0.94 \mathrm{k} \Omega$. $C_{\mathrm{ho}}$ and $R_{\mathrm{ho}}$ are as measured for the HO device: $C_{\mathrm{ho}}=58.6 \mathrm{nF}$ and $R_{\mathrm{ho}}=1.4 \mathrm{k} \Omega$ for $E=7.5 \mathrm{~V} / \mu \mathrm{m}$. 
DC device. As mentioned earlier, the hole current in the HO device is independent on dye doping. So $R_{c}$ and $L_{c}$ take into account all the changes in the device related to the presence of electrons. The inductance $L_{c}$ is needed to account for the delay in the current in its response to the ac field. ${ }^{6}$ Obviously, the combination of the unknown $R_{c}$ and $L_{c}$ together with the measured values of the $\mathrm{HO}$ have to give the right total current in a DC at $20 \mathrm{~Hz}$. This model is particularly suited to show the trends upon dye doping and to present them in a structured way.

The dependence of $R_{c}$ and $\mu_{e}$ on $c$ is shown in Fig. 3, where the absolute values of these parameters are given in the caption. The total current through the device is mainly determined by the values of $R_{\text {ho }}$ and $R_{c}$. In the DC device without dye doping the current is about two times larger than in the $\mathrm{HO}$ device (at voltages $<3 \mathrm{~V}$ ). Upon dye doping $R_{c}$ increases by a factor of 3 . The shallower minimum of the capacitance in Fig. 2 with dye doping is mainly caused by this increase of the resistance $R_{c}$ in the $R_{c}-L_{c}$ branch. $R_{c}$ reduces the current through the branch and, hence, the relative importance of $L_{c}$. The changes in the capacitance minimum therefore are a sensitive probe for the changes in extra conductance and are influenced by the introduction of the negative charge carriers and the presence of dye dopants.

When translating this macroscopic result into a microscopic picture, in principle two borderline cases can be distinguished. First, the extra current density might be predominantly due to electrons. If so, the decrease in $\mu_{e}$ with increasing dye dopant will already explain the increase in $R_{c}$. This possibility is not likely, because in our devices $\mu_{e}$ $\ll \mu_{h}$, see Fig. 2 and the number of electrons and holes are about equal. ${ }^{7}$ The most likely scenario is that the excess current is mainly carried by holes (the other extreme). This is expected, when the space charge clouds compensate each other and allow for additional positive charge carriers to be injected. The region of this compensation grows with in- creasing $\mu_{e}$ and, hence, the lower $\mu_{e}$, the higher $R_{c}$, as observed in Fig. 3. In both scenarios the reduction of $\mu_{e}$ with dye doping can be seen as a natural consequence of the electron trapping ability of the molecular dopant and will govern the device properties of all devices having a similar energy landscape as our model system.

Summarizing, the data show that upon dye doping the DC devices become electron deficient. The changes in $C_{p}$ turn out to be very sensitive for this phenomenon and can be used as a probe for the carrier balance and charge carrier trapping behavior in polymeric LEDs.

The authors acknowledge discussions with Hans Huiberts (Philips), Thijs Michels (TUE), Paul Blom (RUG), Herman Schoo and Jolanda Bastiaansen (TNO), and Hubert Martens (Philips), who suggested the connection between $\mu_{e}$ and the hole current, and thank Dr. Helga Hummel (Philips) and Dr. Volker van Elsbergen (Philips) for the cyclovoltammetry resp. UPS measurements. The work forms part of the research program of the Dutch Polymer Institute (DPI).

${ }^{1}$ H. C. F. Martens, J. N. Huiberts, and P. W. M. Blom, Appl. Phys. Lett. 77, 1852 (2000)

${ }^{2}$ Negative capacitances have been reported before, e.g., in $p-i-n$ structures by F. Lemmi and N. M. Johnson, Appl. Phys. Lett. 74, 251 (1999); Schottky diodes by J. Werner, A. F. J. Levi, R. T. Tung, M. Anzlowar, and M. Pinto, Phys. Rev. Lett. 60, 53 (1988); metal-semiconductor contacts by X. Wu, E. S. Yang, and H. L. Evans, J. Appl. Phys. 68, 2845 (1990); and carbon nanotubes by Y. P. Zhao, B. Q. Wei, P. M. Ajayan, G. Ramanath, T. M. Lu, G. C. Wang, A. Rubio, and S. Roche, Phys. Rev. B 64, 201402 (2001).

${ }^{3}$ H. Becker, H. Spreitzer, W. Kreuder, E. Kluge, H. Schenk, I. D. Parker, and Y. Cao, Adv. Mater. (Weinheim, Ger.) 12, 42 (2000).

${ }^{4}$ M. Meier, S. Karg, and W. Riess, J. Appl. Phys. 82, 1961 (1997).

${ }^{5}$ N. von Malm, R. Schmechel, and H. von Seggern, Synth. Met. 126, 87 (2002).

${ }^{6}$ H. C. F. Martens, W. F. Pasveer, H. B. Brom, J. N. Huiberts, and P. W. M. Blom, Phys. Rev. B 63, 125328 (2001).

${ }^{7}$ P. W. M. Blom and M. J. M. de Jong, IEEE J. Sel. Top. Quantum Electron. 4, 105 (1998). 